\title{
DEVELOPING A ONE STOP SHOP MODEL FOR INTEGRATED LAND INFORMATION MANAGEMENT
}

\author{
E. K. Forkuo and S. B. Asiedu \\ Department of Geomatic Engineering \\ Kwame Nkrumah University of Science \& Technology \\ Kumasi, Ghana
}

\begin{abstract}
In Ghana much attention has not been given to the development of land information system which will integrate the data on land ownership, land use and land value for all the land agencies under the land administration system to facilitate the processing of applications within the land delivery systems. This situation presents a lot of delays and inefficiencies in delivering land services to the investor and other potential clients of land sector agencies involved in the land administration practised in Ghana. This paper describes the development of a one stop shop model for integrating information on the attributes of a parcel and their accessibility. $A$ cross sectional survey was conducted in six land sector agencies in Kumasi on data formats, standards and accessibility in provision of land delivery services to their clients. The results of the survey were then used to design a client server application based on a one stop shop concept to integrate the parcel attribute information. The client server application was designed with Microsoft $S Q L$ Server 2000, VB.Net 2005 and Microsoft Visio. A Land Management Key (LANMANK) program was finally developed with geodatabase capabilities for storing and displaying spatial data as well as other non-spatial data. LANMANK has a unique parcel identifier for land transactions such as land transfers, title registration, property rating, building and development permits processing. Also, it allows the user to create back ups for the database and also restore the database at a later date.
\end{abstract}

Keywords: One stop shop, LANMANK, unique parcel identifier, client server application

\section{INTRODUCTION}

Access to land administration and delivery services provided by the land agencies has been very difficult and very frustrating due to the absence of efficient land information management system. The parcel attributes information such as ownership, value and use of land usually used by these agencies have not been inte- grated in any form to meet the data requirements in the provision of these services. Some of these services include land title registration, building and development permits processing, property evaluation, land transfers and so on.

The absence of an efficient land information management system has brought delays, duplication of services and indiscipline in the land 
market. Consequently people who want to invest in land and the general public lose confidence in the whole land administration system practised in Ghana. There have been projects like the Ghana Country at a Glance (G-CAG) and National Framework for Geospatial Information Management (NAFGIM) to harmonize spatial information in order to increase spatial data accessibility among Ghana government agencies, ministries, the academia and non governmental organizations in the country but little attention has been given to re-engineering the land administration system (Williamson, 2001 ).

In October 2003, a Land Administration Project (LAP) was set up by the government to reform the land administration system so as to make it more efficient. The LAP since its inception has made an attempt to bring all the land agencies under one management in a one stop shop concept. The agencies were to be grouped under four departments; national survey and mapping, human settlement, land services and land registry (Grant, 2004). This paper adopts the one stop shop concept of managing the activities of land agencies in the provision of land delivery services to their clients.

The term "land administration" is used in these Guidelines to refer to the processes of recording and disseminating information about the ownership, value and use of land and its associated resources (UN-ECE, 1996; Enemark et al, 2005). The processes usually involve the determination of rights and other attributes of the land, the survey and description of these, their detailed documentation and the provision of relevant information in support of land markets. Dale and McLaughlin (1999) define land administration as "the process of regulating land and property development and the use and conservation of the land, the gathering of revenues from the land through sales, leasing, taxation, and the resolving of conflicts concerning the ownership and use of the land."

The two definitions stated above clearly identify ownership, values and use (as can be seen in Figure 1) as the three basic attributes of land.
From the two definitions, the function of a land administration system as could be seen from the information management component is an integration of all three components (Enemark and Williamson, 2004; Steudler et al, 2004).

\begin{tabular}{|l|c|c|}
$\begin{array}{c}\text { Juridical } \\
\text { Component } \\
\text { (Land Owner- } \\
\text { ship) }\end{array}$ & $\begin{array}{c}\text { Fiscal } \\
\text { Component } \\
\text { (Land Values) }\end{array}$ & $\begin{array}{c}\text { Regulatory } \\
\text { Component } \\
\text { (Land Use) }\end{array}$ \\
\hline \multicolumn{2}{|c|}{ Information Management Component } \\
Fig. 1: The four basic components of land \\
administration (Steudler et al, 2004)
\end{tabular}

According to Steudler et al (1997) the information management functional component of the land administration system has been developed considerably due to technological advancement in Information Technology (IT) over the last few decades. The one-stop-shop concept describes how the information management component of Ghana's land administration can be developed by integrating data on the other three functional components within a system that ensures easy accessibility of the data by the land agencies.

\section{ONE STOP SHOP MODEL}

One Stop Shop (OSS) is a location, usually a shop, where various requirements can be met in one place. This is a business model that has become commonplace. The theory behind this model is that, by providing many services in one place, shops can offer customers the convenience of obtaining their needs at one stop. Thus the OSS can be adopted as a service end of the information management system if this component is to be developed to enhance land information's accessibility and also increase investors and other potential clients' confidence in Ghana's land administration system. The data and services provided by the land agencies under land administration system can be brought to one location to offer the potential customers the convenience of obtaining their general land transactional needs in one stop 


\section{Forkuo and Asiedu}

(one service point). In this research the OSS model was designed through the following steps:

- A questionnaire survey was conducted at six land agencies to assess them on their data requirement in terms of standards, formats and sources of data;

- The level of usage of Information Communication Technology (computerization) in the land agencies when providing land delivery services to their clients was also assessed;

- Data accessibility within the agencies and outside the agencies was assessed;

- Finally, the kind of restriction an agency puts on redistribution of her data was also assessed.

The responses obtained from four land agencies; survey department, town and country planning, office of the administrator of stool lands and land valuation board were analysed with SPSS (i.e., Statistical Package for the Social Sciences); a statistical software. From the analysis of the responses the following were deduced.

- Most of the land agencies use paper copies of existing data or maps in keeping land records. This makes retrieval of data during processing of applications very difficult and therefore brings about a lot of delays in the land delivery services provided by these agencies;

- In the land agencies it is almost impossible for data on a computer in one office to be accessed on a computer in another office or even in the same office. This is due to the fact that the computers used by these agencies are stand alone computers and so transfer of data is done manually with a storage device. Flat files used in keeping records move from one office to the other with their attending bureaucracies. Some of the agencies therefore place restrictions like copyright, redistribution of data and license agreement on the data in their custody.
- The land agencies seem not to have any problem with data interoperability when an agency receives data from another agency or they are not aware of it since they use the manual way of processing application;

- Parcel identification is done by using the Plot Number, Block Number and Location since the use of Street Name is too ambiguous in the sense that it is difficult to tell the side of the street where the parcel can be found;

- The operating system used by these land agencies is Microsoft Windows and any application that will be developed for these agencies must be compatible with the Windows operating system;

- The use of internet for land records management has not been popular in the land agencies. Where they exist, the internet connection sits on just one computer and it does not contribute towards the efficiency of the land agency;

- Developing an integrated land based information system for the land agencies and other governmental agencies will be achievable since it is accepted by all the four land agencies. They agreed to the need for better co-ordination and joint programs between land agencies and local government with respect to land records creation and maintenance.

\section{A CLIENT SERVER SYSTEM}

The systems architecture was designed by incorporating the results of the cross-sectional survey discussed above in order to obtain an OSS model that can be used to enhance the efficiency of the land agencies in the land delivery service. A client server system was therefore proposed whereby all land agencies will be connected to a common server with a local disk which will store the OSS database. Based on the data dependencies identified in the activities of the land agencies in the land delivery service an institutional framework consisting of three divisions; National Survey and Mapping Divi- 


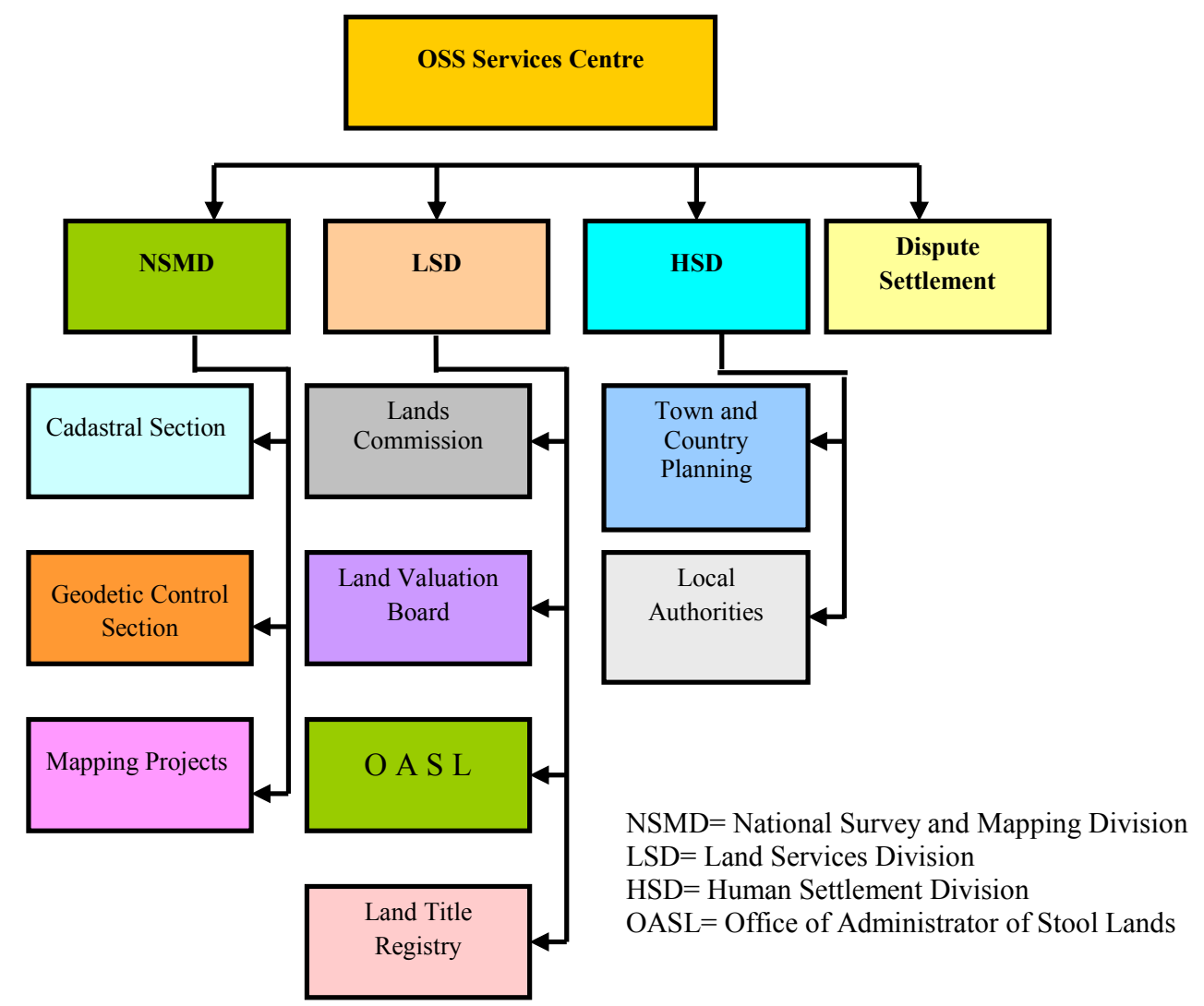

Fig. 2: Institutional Arrangement under the OSS system (as previously envisaged)

sion, Land Service Division and Human Settlement Division together with a Dispute Settlement section.

\section{One Stop Shop Data Modeling}

A geo-database approach was adopted for the OSS database which will store and display maps and textual documents which includes the attributes of map features (parcels). A unique "id" which would run through all transactions at the service centre was also determined. The data models for the OSS database were identified and structured. An abstract of data requirements of the land agencies, services provided by the land agencies and the need of the client was generated from the real world.
The entities of the various datasets drawn from this abstract were then selected. The entities were then mapped into an Entity Relational Model using the Chen Entity Relational Diagram (ERD) with Microsoft Visio to obtain the conceptual model (Kainz, 2000). The conceptual model for the project was formulated as one component but was later subdivided into three models; clients and their needs, land agencies and services they render to the public; and finally parcels and services.

The logical models included the relationships that exist between the entities and the cardinalities between them. The logical data model shows how the data about business entities would reside in the database. It shows how the 


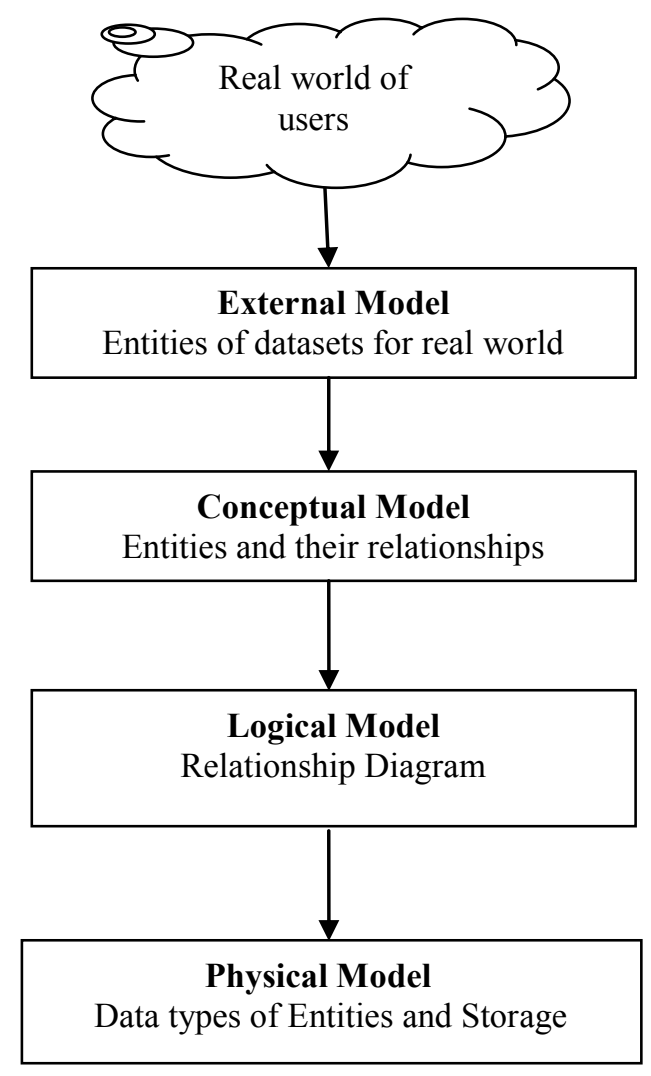

Fig. 3: Data modelling steps (Kainz, 2000)

keys are mapped in terms of Primary and Foreign keys relationships for the entities in order to maintain data integrity. The logical model was also created with the Microsoft Visio by using the database model diagram for setting the database properties.

The physical models were created after reviewing the logical models and also considering the results of the survey conducted at the Land Agencies. The logical model was then exported to Microsoft Access to create the tables for the One Stop Shop database. But due to the fact that Microsoft Access does not support concurrent use and also not a good relational database language, therefore Microsoft SQL Server 2000 was used to design the One Stop Shop database. The tables from the Microsoft Access were edited in Microsoft SQL Server 2000 to save storage space and to facilitate data processing.

This continued with pre-processing activities which involved the preparation of the spatial data before storage in the OSS database. The spatial data generators i.e. National Survey and Mapping Division and Town and Country Planning Division were considered during preprocessing activities. These activities involved the conversion of hard copy data from the divisions stated above into digital format based on similar co-ordinate system and standards.

The standards of the spatial data created include the quality, reliability, classification, accuracy and resolution of graphical and attribute data. The attributes of the digital cadastral plans were reconciled with land title and land registry records in order to ensure easy accessibility and consistency within OSS database created.

\section{LAND MANAGEMENT KEY (LANMANK)}

A Windows based application called Land Management Key (LANMANK) was designed for the One Stop Shop system. It handles spatial data in the vector form (Shapefile), non spatial data in comma delimited formats and images. The program has a spatial data display section, lodgement or application section and a search engine which form the Front Office application.

The program also contains Back Office applications or views for the land agencies which handle the processing of applications from the Front Office. The Lanmank program has the following:

- Ability to display spatial data in the Shapefile format, non spatial data in comma delimited formats and images;

- A search engine for accessing information on all clients' applications, requests and history of all parcel transactions;

- Dispute settlement section for reporting and settling disputes on parcels;

- A unique parcel identifier which contains 


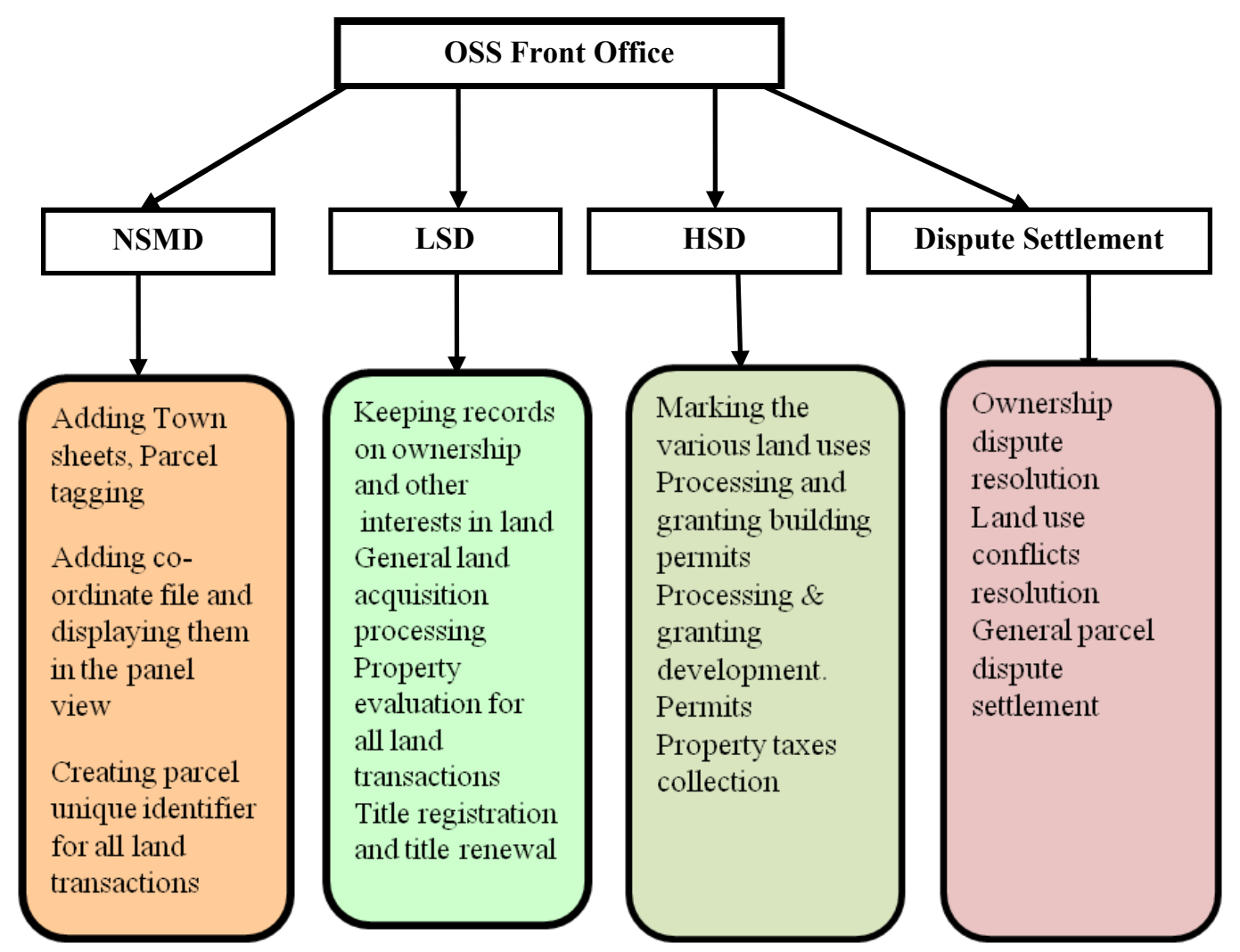

Fig. 4: Activity chart for the land agencies under the OSS System

the image and name of the parcel owner or proprietor, land use, location of parcel interest on the parcel and the registration status of the parcel;

- A lodgement or application section;

- Data security and data access control and monitoring through the use of special user account types such as a general user, restricted user and system's administrator. The editing rights for the users vary from one user to the other; but the system's administrator can do everything within the system like adding and deleting users, determining the database connection settings and uploading base data for the various sections within the One Stop Shop system;

- Creating back ups for the OSS integrated data and setting up of restore points for maintaining the data even if the system fails or crashes;

- Cadastre report section which can be used to produce a cadastre for a particular area or locality.

\section{Merits and Demerits of the LANMANK Pro- gram}

The LANMANK programme reduces time required for processing applications such as title registration, building and development permits drastically by providing efficient data searches and background cross checking of all parcel information. The programme provides efficient data search and storage. Clients application history can be searched with even the first two letters of the clients' first name or surname and date of lodgement. 
It also provides a formal identification or a legal proof of ownership for all land transactions through the unique parcel identifier and performs a lot of data validation checks on the data supplied by the client or the user in order to maintain the standards of the integrated data from the land agencies participating in the OSS system. It has the ability to return the parcel from the parcel leasehold occupant to the original owner when the lease period expires and provides access to reports on all land disputes recorded at the service centre. However, the LANMANK program cannot edit the content of any spatial data apart from displaying it in the Shapefile format in the panel view. Also, it works within 2 dimensional plane with the Cartesian Co-Ordinate System; it can only display the third dimension in a tabular data.

\section{RESULTS AND DISCUSSION}

Figure 5 shows the main interface of the developed LANMANK program. The results of the user needs analysis were factored into the design of the business rules for the program to ensure that the restrictions the agencies put on their data are maintained. All the four agencies who responded to the questionnaires make use of site plans and therefore the display of the site plans was made paramount in the design of the spatial component of the program.

The spatial display section can take different datasets but arrange them in hierarchy starting from regions, district, towns and suburbs or locations. Several maps can be opened in one window but they are placed on "tabs" so a user clicks on a particular tab to display the map of interest. The scale of the original maps is reduced by four times so that they can fit into the screen size but the co-ordinates were restored for the sake of consistency. The program uses maps that are digitized and georeferenced in a GIS environment for instance with ArcGIS software. The accuracies of the maps displayed are limited by that of the source data. The program can preview the spatial data before opening it. Figure 6 shows parcels previewed by the LANMANK program.

block, location and land category or land use can be attached to it. At runtime when a cursor is moved over a tagged parcel a tool tip pops up showing the parcel information. It is also possible to search for parcels that belong to a particular land use or land category. The maps are arranged in a Panel View. It is also possible to search controls within some specified distance

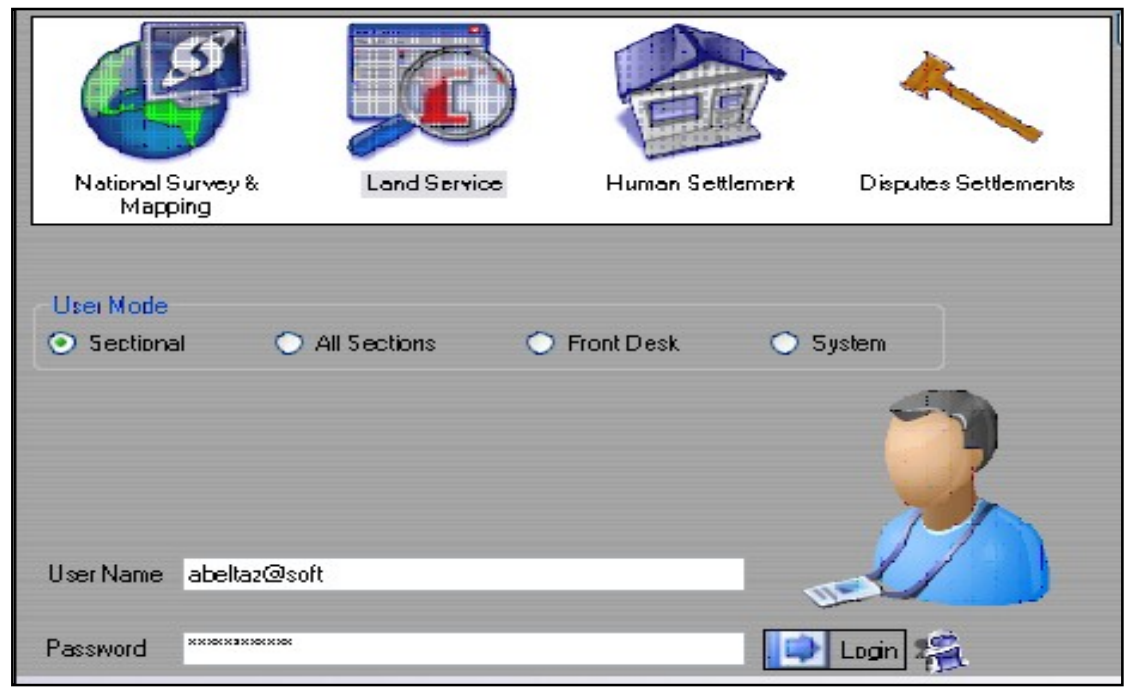

Fig. 5: Main interface of the LANMANK program

Journal of Science and Technology (C) KNUST December 2009 


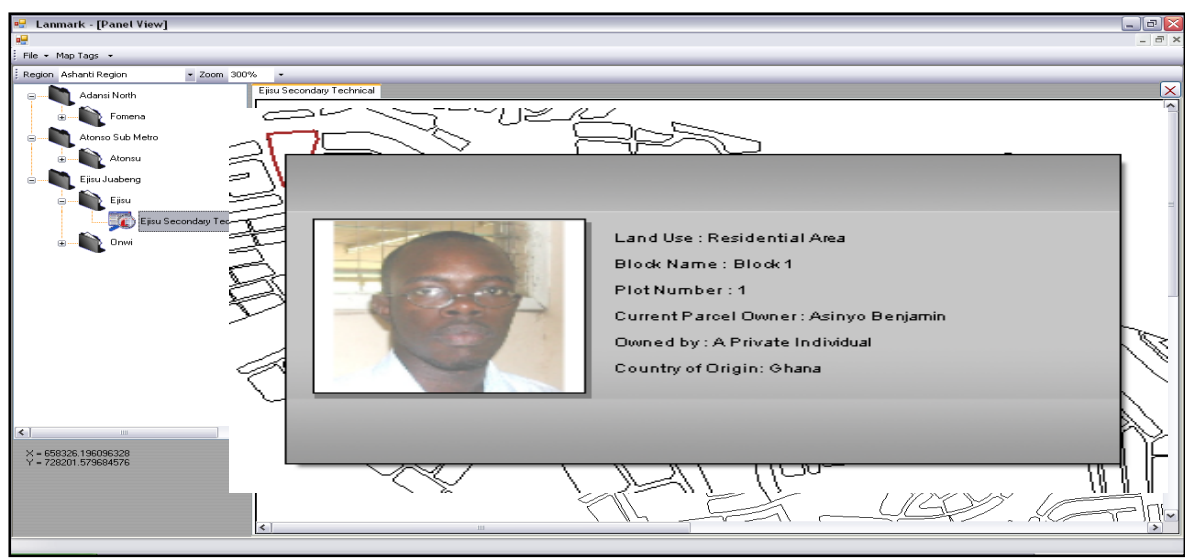

Fig. 6: Spatial data displayed by the LANMANK Program with the unique parcel identifier

from a parcel. The result of the search is returned by red spots showing around the highlighted parcel with a tool tip showing the location, description and co-ordinates of the closest control. As the cursor is moved over the map face co-ordinates of the infinite number of points within the Shapefile populate in the lower left pane of the window.

When a client makes a request or an application is received at the front desk, checks and validations are done to ascertain the correctness of the documents submitted by the client. The personal information of the client is saved in the database in addition to the transaction. The previous transactions can also be seen in the left pane as shown in Figure 7.

On the other hand if they are not enough the system returns an error message and saves that transaction so that it could be edited (as demonstrated in Figure 8). The personal information include name, location, identification number, occupation, address, telephone number and the transaction type can be verified (Figure 9).

Again on the same form the progress of any application can be searched with a search engine. Also, the deed of Transfer window (as can be seen in Figure 10) which shows the details of the grantor and the transaction can be viewed in the developed LANMANK programme. As demonstrated in Figure 11, report on transfer and title registration can be generated and the provisional certificate of the parcel transfer can be previewed (Figure 12).

\section{CONCLUSION AND RECOMMENDA- TIONS}

The LANMANK program integrates all the parcel attributes in one geo-database together with most of the land delivery services which can be accessed easily by the land agencies for all land transactions. It shifts the focus from a process oriented system to a client oriented system. The LANMANK programme streamlines the activities of the land agencies and eventually reduces scattered and restricted access to land records, bureaucracies, delays and duplication of efforts in processing of applications within the land agencies.

The LANMANK programme can promote a time saving, efficient, transparent and business like land service delivery system when implemented in the country's land administration system. The program is capable of instilling discipline in the land administration system in Ghana. Issues of multiple sale of land, encroachment, haphazard development, double allocation, squatting, land racketeering and so 


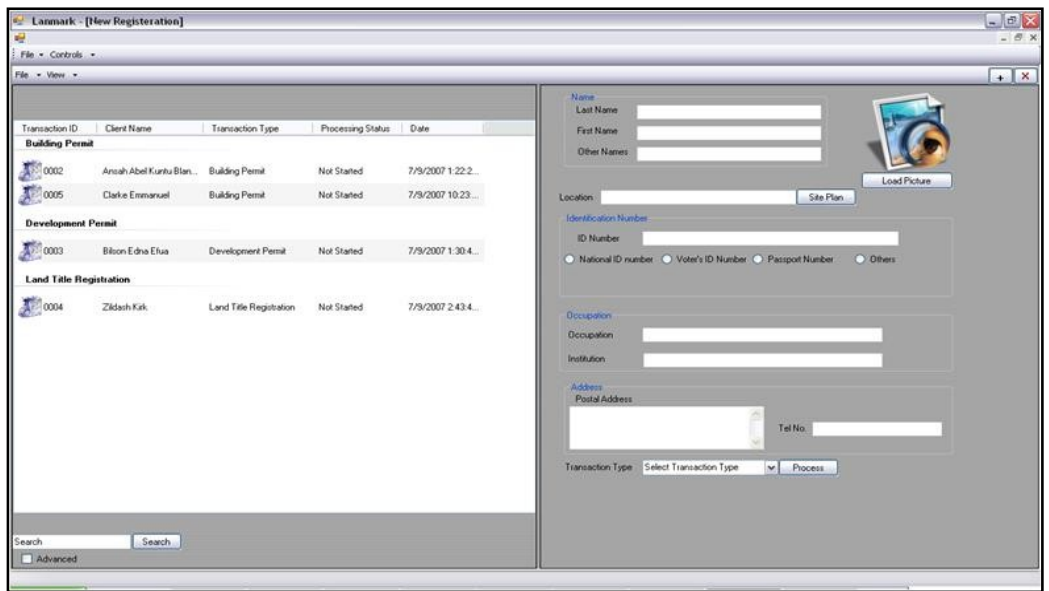

Fig. 7: Transaction Window for making requests and lodgement

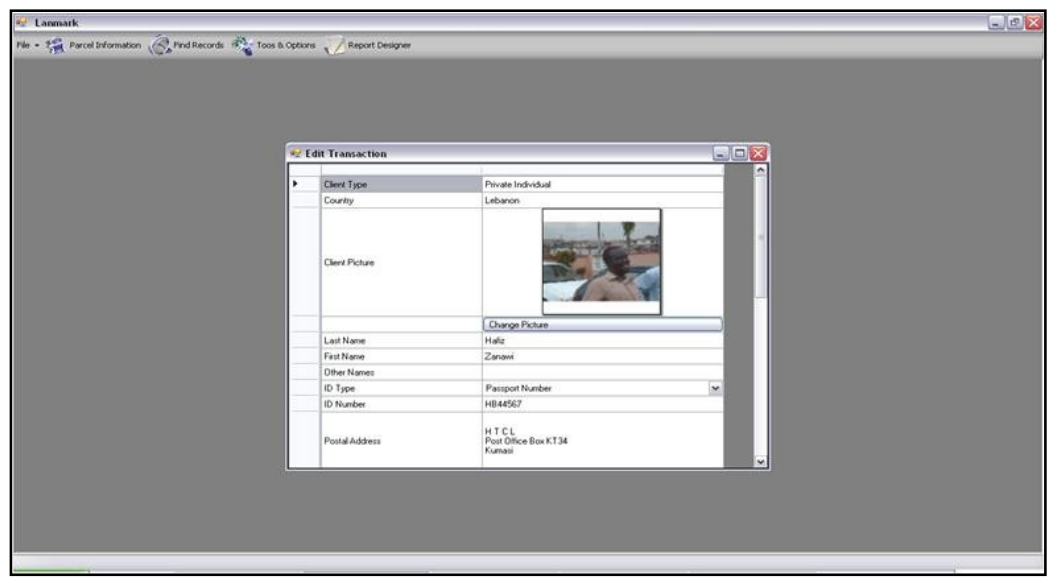

Fig. 8: Editing Client Information

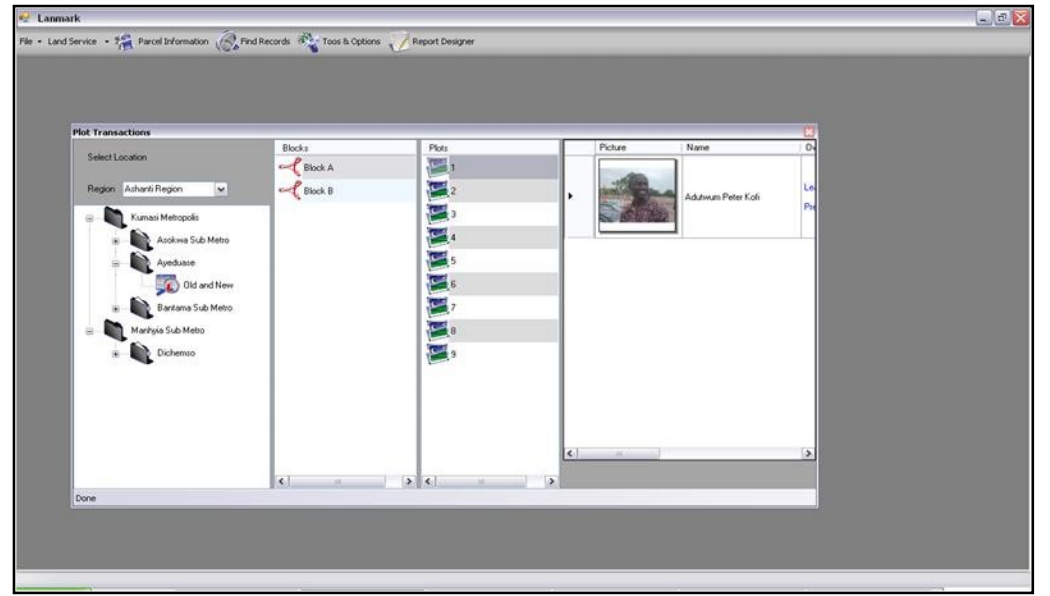

Fig. 9: Verifying the owner of the parcel

Journal of Science and Technology @ KNUST December 2009 


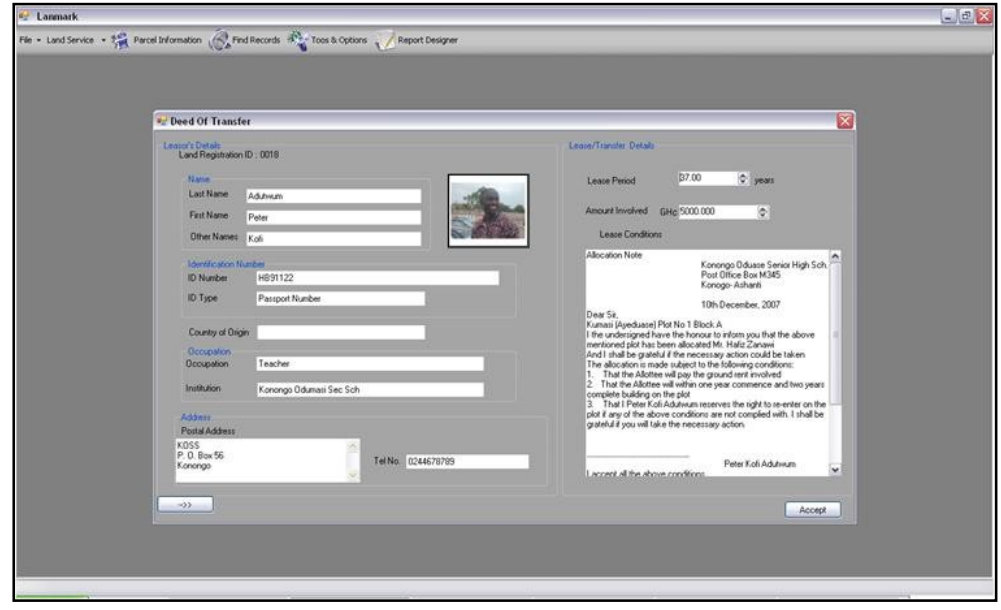

Fig. 10: Deed of Transfer window showing the details of the grantor and the transaction

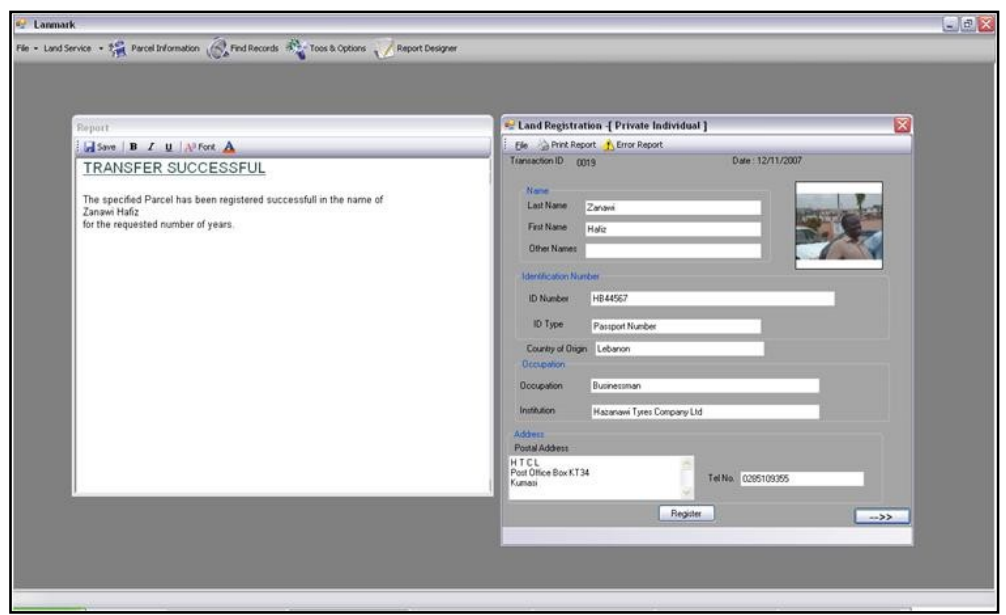

Fig. 11: Report on transfer and title registration

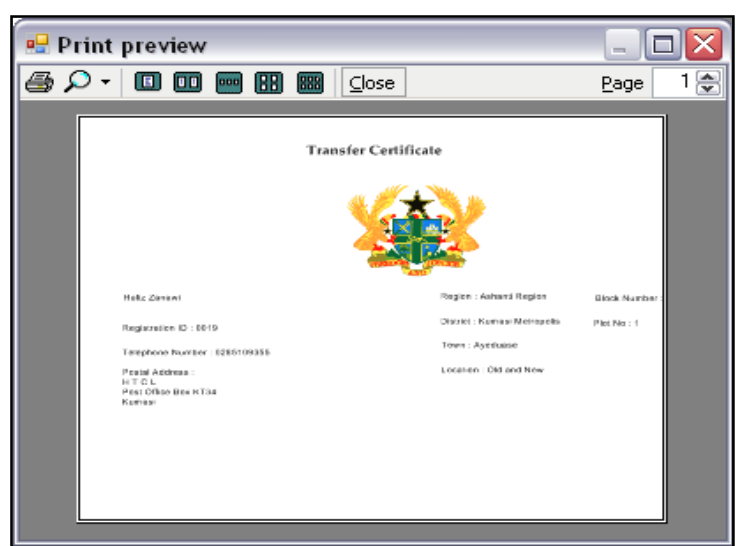

Fig. 12: Preview of the provisional certificate of the parcel transfer 
on would be alleviated and removed totally from the land administration system in the country. This will go a long way to increase client or investor confidence in the real property market and land acquisition in general. However, the future research should look at developing a platform which allows editing of the content of the spatial data such as modifying the geometry of the features within the spatial data and addition of annotations or labels. Also, adding the third dimension to the design of the platform parameters so that it would be possible to display elevation models like contours and if possible Digital Elevation Models (DEMs) (this is critical in the granting of Building or Development permit by the Assembles).

\section{REFERENCES}

Asiedu, S. B. (2007). Developing of an Integrated One Stop Model for Land Information Management, Unpublished MPhil Thesis, Geomatic Engineering Department, KNUST, Kumasi.

Dale, P. and McLaughlin, J. D. (1999). Land Administration Systems. Oxford University Press, Great Clarendon Street, Oxford OX2 6DP.

Eklundh, L., Gyamfi-Aidoo, J. and Mårtensson, U. and Tetteh, E. (1999). Ghana Country at a Glance. A World Bank funded effort to create a geographical database for Ghana. Data Description and Instructions for the use of the G-CAG. Final Report. Accessed: $23^{\text {rd }}$ May ,1999. www.geoinfo.uneca.org/ sdiafrica/country/ghana.

Enemark, S., Williamson, I., and Wallace, J. (2005). Building Modern Land Administration Systems in Developed Economies. Journal of Spatial Science, Vol. 50, No. 2, pp 51-68.

Enemark, S. and Williamson, I. (2004). Capacity Building in Land Administration - A Conceptual Approach. Survey Review, Vol. 37, No 294, pp 639-650.
Grant, D. (2004). Institutional Arrangements, Lands Sector, Ghana, (Unpublished Paper), Ministry of Lands, Forestry and Mines, Accra.

Kainz, W. (2000). The foundation technologies. In: Groot, R. and McLaughlin, J., (editors), 2000, Geospatial Data Infrastructure: Concepts, cases and good practice. Oxford University Press.

Karikari, I. B. (2006). Ghana's Land Administration Project (LAP) and Land Information Systems (LIS) Implementation: The Issue. FIG's Article of the Month February -2006.http://www.fig.net/pub/monthly _articles/fe bruary_2006/ karikari_february_2006.htm. Accessed: $20^{\text {th }}$ May ,2006.

NAFGIM (2001). Geoinfo.uneca.org/.../ghana/ zip/ASDI. Accessed: November, 2005.

Rajabifard, A. (2003). Land Administration Lectures, A Document on Lecture 13; Spatial Data Infrastructures. Accessed: $5^{\text {th }}$ May 2007.

Sagoe, C. (2005). Computer Based Land Information Systems; A Tool for Effective Land Administration in Ghana. Lecture, Ghana Institute of Surveyors $36^{\text {th }}$ Annual Conference, February $11^{\text {th }}$ 2005. www.fig.net/ news/news_2005/ghana_february_2005/ sagoe_ghana_02_2005.p̄df.

Stein, R. D. (2005). CS-M59 - Relational and Object-Oriented Database Systems, Lecture Notes. www-compsci.swan.ac.uk/ $\sim$ csroger/2005CS-M59_1-6.doc. Accessed: $19^{\text {th }}$ October, 2006 .

Steudler, D., Rajabifard, A, and Williamson, I. P. (2004). Evaluation of Land Administration Systems, Department of Geomatics, The University of Melbourne, Victoria 3010 Australia.

Steudler, D., Williamson, I. P., Kaufmann, J. and Grant, D. M. (1997). Benchmarking Cadastral Systems. The Australian Surveyor, 42(3), 87-106. 
One stop shop model for integrated land information management ... 125

Stone, A. (2006). Establishing a Successful One Stop Shop: The case of Egypt, IMF/ AMF High-Level Seminar on "Institutions and Economic Growth in the Arab Countries" Abu Dhabi, United Arab Emirates December 19-20, 2006.

UN-ECE (1996). Land Administration Guidelines with Spatial Reference to Countries in Transition, United Nations, New York and Geneva, 1996.
Vögele, T. (2004). Enhancing Spatial Data Infrastructures with Semantic Web Technologies, $7^{\text {th }}$ AGILE Conference on Geographic Information Science April 29 May $1^{\text {st }} 2004$, Heraklion, Greece.

Williamson, I. P. (2001). Land Administration "Best practice" Providing the Infrastructure for Land Policy Implementation. Land Use Policy 18 (2001) 297-307. 